\title{
El discurso público mapuche: construcción identitaria y diálogo cultural ${ }^{1}$
}

\author{
Luis Nitrihual Valdebenito \\ Universidad de La Frontera (Temuco-Chile) \\ anitrihual@ufro.cl \\ Juan Manuel Fierro Bustos \\ Universidad de La Frontera (Temuco-Chile) \\ jmfierro@ufro.cl \\ Alberto Javier MAYORGA ROJEL \\ Universidad de La Frontera (Temuco-Chile) \\ amayorga@ufro.cl
}

Recibido: 6 de marzo de 2012

Aceptado: 5 de noviembre de 2012

\section{Resumen}

En este trabajo se revisa la noción de discurso público mapuche como complejo textual producido para los medios de comunicación masivos por parte de comunidades, colectivos y agrupaciones ubicadas principalmente en zonas urbanas de Chile. Se plantea la discusión a partir de los conceptos de Iuri Lotman sobre texto, diálogo cultural y construcción de la identidad en los medios de comunicación. Para mostrar como estos discursos (re)construyen una identidad afianzada en la recuperación de una memoria ancestral hemos revisado un pequeño corpus de declaraciones públicas tomadas al azar.

Palabras Clave: Discurso público, Mapuche, Semiótica de la Cultura, Identidad

\section{Public discourse Mapuche. Identity construction and cultural dialogue}

\begin{abstract}
This work reviews the notion of mapuche public discourse as textual complex produced for mass by communities, collective media and groups located mainly in urban areas of Chile. Raises the discussion from Iuri Lotman concepts on text, cultural dialogue and construction of identity in the media. To show how these speeches (re) build an identity entrenched in the recovery of ancestral memory, we reviewed a small corpus of public declarations taken randomly.
\end{abstract}

Keywords: Public Discourse, Mapuche, Semiotics of Culture, Identity.

Referencia normalizada: NITRIHUAL VALDEBENITO, Luis; FIERRO BUSTOS, Juan Manuel; MAYORGA ROJEL, Alberto Javier (2012): "El discurso público mapuche: construcción identitaria y diálogo cultural". Estudios sobre el mensaje periodístico, vol. 18, núm. 2 (julio-diciembre), págs.: 875-890. Madrid, Servicio de Publicaciones de la Universidad Complutense.

Sumario: 1. Problema y contexto sociocultural: el discurso público y lo mapuche como "problema"; 1.1. Lo mapuche como "problema". 2. Interculturalidad y conflicto: el caso chileno. 3. Discurso público mapuche: información e identidad. 4. Una vuelta al pasado: recuperación de lo ancestral e información. 5. Referencias bibliográficas. 6 . Anexos

${ }^{1}$ Este artículo recoge resultados de los siguientes proyectos de investigación: Proyecto DI11 0006, financiado por la Universidad de La Frontera; también corresponde a parte del Proyecto financiado por el Fondo Nacional de Desarrollo Científico y Tecnológico de Chile, FONDECYT n ${ }^{\circ}$ 1120904: "Medios de comunicación, discursos y poder: representaciones e imaginarios sociales sobre la justicia/injusticia en torno al "conflicto Estado-nación y pueblo mapuche" en los relatos producidos por la prensa y sujetos de la Región de la Araucanía." 


\section{Problema y contexto sociocultural: el discurso público y lo mapuche como "problema".}

La investigación sobre lo que se ha denominado Discurso Público Mapuche (DPM) (CARRASCO, H. 1996, 1998a, 1998b, 2000, 2002a, 2002b, 2002c, 2003, 2005) ha sido una de las aportaciones más relevantes, desde los estudios en comunicación, sobre la denominada problemática mapuche y las relaciones interculturales entre el pueblo mapuche y la sociedad y Estado chileno. Particularmente, estas investigaciones se han ocupado de la importancia de las diásporas indígenas en distintas ciudades de Chile y de la producción discursiva mediatizada (PEÑAMARín, 2008: 68) que han realizado estos y que busca establecer un diálogo con la sociedad mayoritaria en base a la exposición de: 1) problemas coyunturales que constituyen el carácter informativo de sus textos; 2) demandas por su legitimidad cultural; 3) un importante proceso de reafirmación identitaria que busca (re)construir una identidad basándose en la recuperación de su memoria ancestral (historia política pasada, sistemas míticos, historia cultural)

En esta medida, en este trabajo se persiguen los siguientes objetivos: a) hacer una revisión de los trabajos publicados acerca del discurso público mapuche; b) revisar lo anterior buscando aportar nuevas perspectivas desde las nociones de diálogo cultural, texto e identidad que hemos tomado de los trabajos del ruso Iuri LotMAN (1996) y; c) revisar un pequeño corpus de declaraciones públicas donde mostramos como, junto con información contingente sobre demandas sociales, en estos textos se intenta reconstruir y proyectar una identidad que dialoga, desde la tensión, con la cultura occidental, ahora también devenida propia en un híbrido particular.

\subsection{Lo mapuche como "problema"}

Para contextualizar muy brevemente la problemática mapuche, podemos señalar que esta se vincula con varias situaciones interculturales presentes en Chile: a) un proceso de relegación y exclusión del pueblo mapuche, debido particularmente a la intervención del Estado chileno en la llamada "Pacificación de La Araucanía". Esta intervención consistió en una arremetida militar en 1861 contra los poblados ubicados al otro lado de La Frontera, en el sur de Chile, y que hasta entonces habían guardado importantes grados de autonomía sobre estas tierras. Esto último legalmente afianzado en los parlamentos firmados por el pueblo mapuche y la Corona Española. De este modo, como puede presumirse, se redujo a los mapuches a pequeñas porciones de territorio denominadas "reducciones" lo que llevó, entre otros factores, al empobrecimiento y marginalidad de estos grupos minoritarios; b) debido a esto, en la actualidad sobre todo, ha resurgido con fuerza un conflicto entre grupos mapuches y Estado chileno y, lo que es el tema de este artículo, esto ha sido llevado a la discusión pública mediante lógicas de mediatización de sus demandas; c) en esto se observa que los grupos mapuches han producido textos monolingües y bilingües (español y mapudungun ${ }^{2}$ ) donde demandan del Estado y de la sociedad en su conjunto soluciones puntuales ante problemas contingentes, pero también reconstruyen discursivamente su cultura originaria.

\footnotetext{
${ }^{2}$ Lengua del pueblo mapuche.
} 
Nos encontramos, sin más, ante procesos de resistencia cultural, por un lado, con discursos que se mueven de manera vertiginosa en los flujos mediáticos actuales, $\mathrm{y}$, por otro lado, con intentos de proyectar una identidad que los moviliza como colectivo y que les permite continuar sus procesos reivindicatorios.

\section{Interculturalidad y conflicto: el caso chileno}

Es evidente que el contacto entre hombres de distintas culturas puede remontarse a los albores de la civilización, pero también es cierto que el abordaje metodológico y disciplinario de la comunicación interculturalidad comienza a configurarse sólo en la segunda mitad del siglo XX y exige hoy más que nunca, sobre todo debido al aumento de los flujos migratorios, el estudio de los procesos de diólogo entre culturas en contacto.

Como señala Del VAlLe (2004) las primeras investigaciones bajo el concepto de interculturalidad pueden situarse definitivamente, aunque ya existiesen antecedentes, en los trabajos de Stuart HaLl en los años 60 del siglo XX, quien menciona por primera vez el concepto intercultural communication. En el contexto de HALL, estas investigaciones se vinculaban con minorías afrodecendientes:

"Así, la comunicación intercultural, como campo de estudio; lo étnico, como objeto de estudio; y el indígena y el inmigrante, como sujetos de estudio, emergen de experiencias sociopolíticas y económicas traumáticas: migraciones a gran escala, principalmente en Europa, y reivindicaciones y demandas, particularmente en Latinoamérica" (Del VAlLe, 2004: 174).

De este modo, la comunicación intercultural, como veremos en el caso de Chile, pero también en muchos otros lugares, ha estado cimentada sobre el conflicto y la violencia. Particularmente en América, como bien señala ABRIL (2007), el proceso de entrecruce cultural produjo un sincretismo que antes que negociación fue un modo de sobrevivencia cultural.

En este sentido, el desencuentro de la cultura mapuche con la cultura huinca ${ }^{3}$ ha estado presente desde la llegada de los conquistadores españoles. Estos lograron asentar su soberanía hasta los márgenes del río Bío Bío, en el sur de Chile, desde donde la resistencia indígena se hizo intensa y logró definitivamente negociar su autonomía con la Corona Española.

LEÓN (2007) señala como llamativamente cuando se produce la invasión del Estado chileno en estos territorios, con el consiguiente proceso de "civilización" de los "indios", el principal grupo descontento fueron los meztizos. Esto se debió a que la zona de La Frontera, como bien le entrega importancia LotMAN (1996), tuvo un intenso flujo de relaciones culturales que consolidaron formas de hacer, estilos de siembra, de cosecha y rituales propios del sincretismo y la negociación que se da en las fronteras. Esto, no obstante, se vio cortado de manera violenta con los procesos de aculturación pacífica y con las matanzas perpetradas por el ejército chileno en 1862 (BENGOA, 1985).

${ }^{3}$ Huinca es una palabra mapuche utilizada para denominar al extranjero. 
Por esta razón, entenderemos la interculturalidad, en el marco de este trabajo, como una situación de coexistencia entre grupos culturalmente diversos y que produce situaciones de simetría/asimetría en sus relaciones sociales (CARRASCO, H.: 2005, 7) y particularmente en la producción discursiva, que es lo que aquí nos interesa.

Es importante tener en cuenta esta definición de interculturalidad para no confudirla con multiculturalidad, entendida, desde nuestro punto de vista, como una propuesta política de coexistencia más o menos asimétrica (JAMESON y ZiZEK, 1998) entre grupos culturalmente diversos. La interculturalidad se encuentra más en el estadio de las relaciones de esos grupos culturalmente diversos. Es allí donde es posible establecer problemáticas necesarias de evidenciar para contribuir a ensanchar los márgenes de la comunidad y la visibilización de los sujetos sociales.

\section{Discurso público mapuche: información e identidad}

Dentro de un marco general de interculturalidad es posible constatar que se abre un espacio desde el discurso para indagar en las relaciones que este pueblo mayoritario tiene con las minorías indígenas y viceversa. De este modo nos acercamos a una interculturalidad textual, (CARRASCO, H. : 2005a) espacio en que la situación de los mapuches urbanos que utilizan los medios de comunicación para hacer saber sus reivindicaciones, se nos propone como un proceso complejo e hibrido. Complejo en el sentido de plurivocálico e híbrido como producto del cruce natural de voces. Evidentemente ya no se trata de los textos orales aún en uso en la cultura mapuche (CHAlin, NgÜlam, Pentukum, EpëU, etcétera), sino de textos periodísticos que retomando algunos elementos de esta tradición ancestral trasladan a la discusión pública sus demandas políticas y culturales.

En esta medida, el discurso público mapuche entendido como un discurso dirigido hacia instancias nacionales e internacionales (CARRASCO, H: 2002) está constituido por declaraciones públicas, comunicados de prensa, notas de prensa, entre otros textos políticos y periodísticos (CONTRERAS, 2002: 30). En estos, grupos mapuches, comunidades establecidas, asociaciones y colectivos, a través de los medios masivos de comunicación (radio, prensa, televisión, internet) difunden textos intensionalmente producidos para reclamar sus derechos, apelar a la sociedad chilena y reafirmar su identidad.

Dentro del trabajo desarrollado por Hugo CARRASCO y el grupo de investigación por el dirigido, hay que señalar tres puntos relevantes en cuanto a la configuración del discurso público mapuche:

1) El concepto de discurso público es retomado de los trabajos de Gerard IMBERT (1984) y señala aquellos discursos donde interactúan los sujetos sociales, "lugar de intercambio de los discursos y de plasmación de la identidad" (IMBERT, 1984:165). Lo público, en esta medida, es entendido como el espacio de hacer y construir en común y siguiendo a Cristina PeÑAMARÍn (2008: 62) los medios de comunicación en la modernidad se encuentran imbricados de manera importante en la construcción de lo público. No olvidemos que tal como señala THOMPSON (1998), en la actualidad conocemos el mundo a través de los medios de comunicación y estos tienen una gran importancia en la construcción de las identidades. 
2) Por otro lado, los trabajos de Bomfil Batalla (1987) dan pie para entender los fenómenos interculturales como procesos de defensa de la cultura propia y apropiación de elementos de la cultura ajena, todo esto en la idea de control cultural y donde se observa que los grupos étnicos minoritarios retoman las estrategias narrativas de la cultura ajena para hacer escuchar sus demandas. De este modo se produce una problemática identitaria interesante pues se reafirma la identidad como colectivo sobre la base de estrategias de la otra cultura. Es necesario apuntar, en este sentido, que la cultura mapuche es una cultura tradicionalmente ágrafa y que la incorporación de la escritura es más bien tardía.

A este concepto de apropiación trabajado por Hugo CARRASCO a partir de Bomfil BATALLA, nosotros agregaríamos la pregunta formulada por LOTMAN (1996: 64) ¿cuándo y en qué condiciones un texto "ajeno" es necesario para el desarrollo creador del propio? O puesto de otra forma, el contacto como ese otro yo, que en este caso es la cultura occidental, constituye una condición necesaria para el desarrollo creador de la conciencia.

En el caso de los mapuches, el desarrollo creador, a partir de la incorporación de la escritura, ha posibilitado la concreción de una producción discursiva heterogénea y compleja. Un ejemplo de esto lo constituye la poesía mapuche. Esta ha supuesto una apertura del canon chileno y muestra rasgos, como el carácter híbrido, del discurso público mapuche. Por esto habría que señalar qué la condición plurivocálica es propia de los textos producidos por mapuches y aún más, es condición general de todo texto. El poeta Juan Paulo Huirimilla (2003) escribe en su poema Bandas de Rogativa:

\author{
Cuando damos vuelta en pasacalles \\ A la virgen loca Pillancura \\ Con dos maderos negros que arden \\ No parlamentamos a su dios \\ Tan adornado de oro y palomas \\ Es Ngenmapun que danza \\ En la pampa \\ Hacia la casa de estrella y luna \\ Del cielo.
}

Se trata de una escritura que retomando las estrategias de la poesía tradicional posiciona su propio acervo cultural y esboza críticas a la cultura impuesta, en un diálogo evidente con esa tradición del dios adornado de oro. No es ese dios el que se encuentra en el centro del texto poético de Huirimilla, es el Ngenmapun, sin embargo ese dios de oro es una posición necesaria para reconocerse. Por esta razón el desarrollo creativo de estos textos se encuentra indisociablemente ligado a la otra lengua pues:

"Toda polémica exige un lenguaje común entre los adversarios: en este caso el lenguaje del adversario pasa a ser ese lenguaje, pero al mismo tiempo es sometido a anexión cultural, lo que trae consigo el desarme semiótico de la otra parte" (LOTMAN, 1996: 73). 
3) Un tercer elemento importante y que constituye el núcleo teórico del discurso público mapuche, es la idea de complejo textual que acuñara Iván CARRASCO (1979) para entender la heterogeneidad discursiva. Hoy agregaríamos a esta visión, siguiendo a Lotman (1996), que todo texto es heterogéneo por naturaleza, aún más en estas condiciones interculturales. En el discurso público mapuche se observa un "nosotros" afianzado en la voluntad de reconstruir y proyectar una memoria pasada y un "otro" visto como el "opresor" y donde los enunciadores se leen como un sujeto colectivo participe de una experiencia social del trauma y la violencia.

\section{Una vuelta al pasado: recuperación de lo ancestral e información}

Uno de los rasgos que nos interesa clarificar en este trabajo es cómo los discursos públicos que hemos tomado para analizar, tomando las estrategias del discurso periodístico, posicionan un nivel informativo donde como señala Cristina PEÑAMARín el texto cumple una de sus funciones:

"El texto es un hecho social y cultural. El texto está ubicado en un espacio y un tiempo, un soporte material, unos intereses, unas condiciones y unos modos de producción, de difusión y de uso, unas tradiciones y saberes sociales y culturales. El texto construye su significado por referencia a un contexto determinado. El sentido "lingúístico" es un punto de referencia necesario para la interpretación, pero ésta se realiza considerando los efectos que su autor previó en un destinatario situado" (PeÑAMARín, 1997: 147).

Cada declaración pública que hemos revisado para este trabajo comienza con las razones para la emisión del comunicado de prensa y este siempre se encuentra ligado al contexto social que hemos señalado anteriormente y del cual habla PeÑAMARín. Por ejemplo, en esta declaración del 2004 el discurso se articula sobre una crítica ante los procesos judiciales contra mapuches:

Frente a la sistemática represión que el Estado chileno desarrolla en contra de personas y comunidades mapuche y que durante estos días ha intensificado para dar continuidad a los procesos judiciales arbitrarios y condenatorios de nuestros hermanos mapuche, DENUNCIAMOS lo siguiente: (COORDINADORA DE COMUNIDADES EN CONFLICTO, 2004).

En otros textos se produce una suerte de anclaje con un nivel informativo periodístico que anticipa a un receptor medianamente desinformado y que muestra como uno de los posibles destinatarios a los cuales se dirigen estas declaraciones es la opinión pública internacional.

En la precordillera de la 8 va región, a 85 kilómetros de Los Ángeles, zona donde nace el río Bio Bio se inauguró en marzo de 1997 la Central Hidroeléctrica Pangue, la primera de un megaproyecto de 6 represas generadoras de electricidad (Coordinadora mapuche Región Metropolitana, 1997).

Con fecha 20 de Septiembre nos propusimos recuperar 66 hás de tierra que nos tiene usurpada el Fundo Santa Rosa de Kolpi, hoy propiedad de la Forestal Mininco. Hemos permanecido ya por 10 días en nuestra tierra, en el transcurso de estos días hemos tratado de conversar con los representantes de la Empresa, quienes se han negado a recibirnos, 
nuestra intención es establecer una conversación con los representantes de la forestal para fijar plazos de entrega y la necesaria indemnización que nos debe hacer la Empresa por los más de 70 años que han usufructuado de nuestra tierra (COMUNIDADES EN CONFLICTO, 1998).

Cómo puede verse, las estrategias informativas de estos textos se plantean como una forma de hacer saber sus demandas. Problemas todos vinculados con los duros procesos de recuperación territorial y con sus acusaciones de violencia política y policial ejercida por parte del Estado chileno (caso del primer fragmento expuesto) En esto cabe preguntarse como el Estado, disminuido en Chile por los procesos de liberalización llevados a cabo en la década de los 80 bajo la dictadura militar, continua actuando con fuerza para reprimir a los grupos indígenas. Esta violencia queda demostrada en que actualmente los procesos contra mapuches son sancionados por la Justicia Militar y a los imputados se les puede aplicar la Ley Antiterrorista.

Pero junto con este nivel informativo, el discurso público mapuche presenta una (re)construcción de la memoria ancestral. En la siguiente declaración pública de la Asociación Xeng-Xeng, el relato se inicia como un recorrido histórico donde hay referencias a una cultura que se reconoce como distinta y que permite ejecutar el juego de la diferencia.

1) Xeng-Xeng, es un territorio mapuche histórico de unas 300 hectáreas, donde nuestros antepasados llegaron a establecerse provenientes de la guerra de Arauco. Allí realizaban sus ceremonias sagradas como NGUILLAIMAWUN, WEUPIN, además es una montaña que sobresale por su altura y belleza ante todas las comunidades indígenas que la rodean, en ella se guardan ricas historias y creencias de los mapuches del sector, como la montaña sagrada que les brinda el agua, la vida y el remedio que curan sus males y dolencias. (XenG-Xeng, 1997).

LOTMAN (1996) nos recuerda que un texto cumple una función no sólo de transmisión de información, como ocurre en estos comunicados públicos que acusan determinados problemas coyunturales, sino que además transmiten la herencia cultural y una identidad siempre compuesta y en continua composición. El discurso público mapuche, de este modo, es un texto híbrido pues, a nuestro juicio, la proyección de la identidad actual se configura a partir de las dos visiones. Una se lee en la otra y ambas construyen un relato en tensión. Esto es especialmente evidente en comunicados como el siguiente:

Hoy estamos frente a los más íntimo y sagrado de nuestro pueblo, frente a Nguillatue. Es tiempo dicen muchos de modernización. Esta modernización, sin embargo arrasa con toda esencia del ser humano. Para nuestro caso, la modernización ha destruido el sistema comunitario de vida, nuestro Ngenko, Rehue, Nguillatue, Kupalhue... El sitio sagrado Nguillatue fue avasallado por la presencia de máquinas que abrieron heridas en nuestro territorio. Posteriormente,... se gesta una segunda profanación de los sitios sagrados mapuches, esta vez no basto la máquina sino la dinamita para destruir la tierra y con ello imponer la carretera. Con estas dos incursiones maléficas se deteriora la integridad de los espacios sagrados Llankupi, Wicilko, Xayenko, Kurihuentru, todos los cuales se altera su condición 
natural y se le destruye el hábitat a las aves y animales silvestres que conviven en la comunidad mapuche (XENG-XENG $\left.{ }^{4}, 1997\right)$.

Como puede verse, este texto nuevamente presenta una información puntual que tiene que ver con la profanación de sitios que los mapuches consideran sagrados. Esto en beneficio de una modernización abusiva. Para contextualizar esta demanda debemos señalar que durante 1997 se produjo una lucha, fundamentalmente mediática, llevada a cabo por mapuches de la zona del Alto Bío Bío quienes se negaban a vender sus tierras. En este lugar, Endesa, con favor del gobierno de turno, construyeron una red hidroeléctrica que supuso finalmente la inundación de miles de hectáreas. Esta historia fue llevada al debate público de manera intensa pues durante la construcción de la represa, contraviniendo cualquier normativa internacional, fueron arrasados cementerios y zonas sagradas indígenas.

Este comunicado se inserta, por otro lado, en una red textual con otras declaraciones públicas que logran unificar la mirada que los colectivos mapuches tienen sobre este problema puntual.

Actualmente pese a no contar con la autorización definitiva, se esta instalando maquinaria pesada para iniciar los trabajos de la segunda represa, RALKO, la cual inundaría 3.400 hectáreas de territorio Pewenche, previa erradicación de las familias allí asentadas por siglos (COORDINADORA MAPUCHE REGIÓN METROPOLITANA, 1997).

Esta característica del discurso público mapuche sobresale. Se trata de la articulación narrativa desde un presente de la enunciación y que se va retrotrayendo hasta llegar a un pasado lejano de opresión:

En el día de hoy se cumplen 505 años de la llegada de los conquistadores Españoles a nuestro territorio, en esta fecha ha cambiado radicalmente nuestras vida como pueblos indígenas (XENG-XENG).

Un presente que tiene fecha de inicio y que permite anticipar que el relato que sigue es la enumeración de las diferencias con esa otra concepción del mundo. Esto contribuye a crear a un "otro" (Estado chileno, Corona Española, ejército español, ejército chileno) como oponente y a recrear un pasado mejor que el momento de enunciación.

De esta forma los textos producidos por mapuches urbanos, tanto de discursos públicos como de poesía, se encuentran articulados como dispositivos que trasladan las funciones que tradicionalmente tenían otros tipos textuales orales y que a nuestro modo de ver buscan reafirmar una identidad como pueblo vinculado a la tierra, a la comunidad y a la posesión de determinados territorios y no otros.

El problema identitario que surge de este dispositivo de información y transmisión de la herencia cultural heredada de forma fundamentalmente oral y por el estudio del relato historiográfico, es interesante. Hace preguntarse como los medios de

${ }^{4}$ Colectivo mapuche urbano, extracto tomado del trabajo de Verónica ConTRERAs (2002: 34) 
comunicación, dispositivos de la fugacidad, permiten la búsqueda de construcciones identitarias que buscan solidificar los diversos sentidos de pertenencia que legítimamente tienes los sujetos de una comunidad.

Esto obliga a preguntarse también si el discurso público mapuche es una fenómeno de defensa de la cultura propia, o de mera reproducción de la cultura ajena, lo que constituye el núcleo de la problemática de la identidad, que no se resuelve al margen de la lengua y los otros lenguajes de la cultura, entre los cuales el discurso mítico-creencial es uno de los fundamentales (CARRASCO, H., 2002:13).

Finalmente, a esta pregunta señalada por Hugo Carrasco, podríamos aportar con una respuesta que señale que los textos producidos por mapuches muestran una identidad flexible. Ya no se trata de un estado identitario ancestralmente neutro y sólo de cultura propia, sino que los sujetos de enunciación se encuentran cruzados por dos matrices culturales que se evidencian en el discurso como dos actantes (la cultura propia y la ajena) en tensión.

Esta construcción de la identidad en medio de la fugacidad de los medios de comunicación, incluido hoy Internet queda aún más claro en el encabezado del siguiente comunicado:

La familia mapuche se reúne, para reconocerse y decir que está orgullosa de ser mapuche, que nuestros rostros, apellidos, costumbres, sangre, como también nuestro lugares de origen, son algunas de las cosas que tenemos en común y que aunque estamos en una gran ciudad queremos y debemos estar unidos, diciendo soy parte del Pueblo Mapuche (COORdinadora mapuche Región Metropolitana, 1997).

\section{Referencias bibliográficas}

ABRIL, Gonzalo (2007): Análisis crítico de textos visuales. Madrid, Síntesis.

ABRIL, Gonzalo 1997 (2005, 2a ed.): Teoría General de la Información. Datos, relatos y ritos. Madrid, Cátedra.

BENGOA, José (1985): Historia del pueblo mapuche. Siglo XIX y XX. Santiago de Chile, Ediciones Sur. Colección Estudios Históricos.

BETANCOUR, Sonia (2004): "El discurso público mapuche estudiantil”. Revista Lengua y Literatura Mapuche, $\mathrm{n}^{\circ}$ 11, pp.195-113.

BOMFIL Guillermo (1987): "La teoría del control cultural en el estudio de procesos étnicos". Revista Papeles de la Casa Chata. Año 2, nº 3.

CARRASCO, Hugo (1987): "Tren Tren y KaiKai: segundo nacimiento en la cultura mapuche". Estudios Filológicos 21:23-44.

CARRASCO, Hugo (1988): “Un mito 'anterior' a Trentren y Kaikai”. Estudios Filológicos 23: 7-37.

CARRASCO, Hugo (1996): "El discurso público mapuche". Revista Lengua y Literatura Mapuche 7, vol.1, pp. 107-117. Universidad de La Frontera. 
CARRASCO, Hugo (1998a): "El mito del Estado Mapuche: discurso público y poesía". Actas Noveno Congreso Internacional de la Sociedad Chilena de Estudios Literarios. Valdivia, Instituto de Lingüística y Literatura, Universidad Austral de Chile, pp. 56-61.

CARRASCO, Hugo (1998b): "La lógica del discurso público mapuche”. Revista Lengua y Literatura Mapuche, n ${ }^{8}$, pp. 203-216.

CARRASCO, Hugo (2000): "Los tipos discursivos del discurso público mapuche". Revista Lengua y Literatura Mapuche, n 9, pp. 145-156. Universidad de La Frontera.

CARRASCO, Hugo (2002a): "El discurso público mapuche: noción, tipos discursivos e hibridez". Revista Estudios Filológicos, nº 37, pp. 185-197. Valdivia, Universidad Austral de Chile.

CARRASCO, Hugo (2002b): "El discurso público mapuche: procedimientos textuales identitarios". Revista Universum, ${ }^{\circ}$ 17, pp. 11-27. Universidad de Talca.

CARRASCO, Hugo (2002c): "El discurso público mapuche: complejo textual polisistémico producido para la prensa". Revista Comunicación y Medios, $\mathrm{n}^{\circ} 13$, año 13, pp. 60-74

CARRASCO, Hugo (2003): "Notas sobre la organización retórica de los discursos públicos mapuches". Revista Texto, Lingüistica y Cultura. Comunicaciones seleccionadas. Osorno, Universidad de Los Lagos-Sochil, pp. 85-100.

CARRASCO, Hugo (2005): "El discurso público mapuche: comunicación intercultural mediatizada". Revista Estudios Filológicos, no 40, pp. 49-64. Universidad Austral de Valdivia

CARRASCO, Iván. (1979): "Dos discursos complementarios: las dedicatorias y las notas". Revista Estudios Filológicos, n 14, pp. 129-137.

CONTRERAS, Verónica (2002). "La construcción narratológica en el discurso público mapuche". Revista Universum, no 17, pp. 29-36. Universidad de Talca.

DEL VALLE, Carlos (2004): "Genealogía crítica de la comunicación intercultural: mediocentrismo e invisibilización de lo étnico en los estudios interculturales". Revista Sphera Pública, 004, pp. 171-196.

HUIRIMILLA, Juan Paulo (2003): Palimpsesto. Temuco, Editorial Nuevoarte.

IMBERT, Gerard. (1984): "Sujeto y espacio público en el discurso periodístico de la Transición. Hacia una sociosemiótica de los discursos sociales". En GARRIDO, Miguel Ángel et al.: Teoría semiótica. Lenguajes y textos hispánicos. Madrid: C.S.I.C.E

JAMESON, Frederic y ZIZEK, Slavoj (1998): Estudios Culturales. Reflexiones sobre el Multiculturalismo. Buenos Aires, Paidós.

LOTMAN, Iuri (1996): La Semiosfera I. Semiótica de la cultura y del texto. Madrid, Frónesis. 
LEÓN, Leonardo (2007): "Tradición y modernidad: Vida cotidiana en la Araucanía (1900-1935)" Historia (Santiago) [onlinPe]. 2007, vol. 40, no. 2, pp. 333-378. Disponible en: < http://www.scielo.cl/scielo.php?script=sci_arttext\&pid=S0717$71942007000200004 \& \operatorname{lng}=$ es\&nrm $=$ iso $>$. ISSN $0717-719 \overline{4}$.

OTAZO, Jaime. (2002): “Aspectos identitarios del actual discurso público mapuche" Revista Universum, $\mathrm{n}^{\circ} 17$, pp. 187-197.

PEÑAMARÍN, Cristina (2008): “¿Hay vida política en el espacio público mediatizado?". Revista CIC, Cuadernos de Información y Comunicación, vol. 13, pp. 6178.

PEÑAMARÍN, Cristina (1997): "El análisis de textos en una nueva clave. Discursos e imágenes sobre la inmigración en El País" Revista CIC, Cuadernos de Información y Comunicación, $\mathrm{n}^{\circ}$ 3, pp. 145-166.

BENGOA, José (1985): Historia del pueblo mapuche. Siglo XIX y XX. Santiago de Chile: Ediciones Sur. Colección Estudios Históricos.

THOMPSON, John B. (1998): Los medios y la modernidad. Barcelona, Paidós.

\section{Anexos}

\section{Declaración pública de la Coordinadora Arauco Malleco. 30 de julio de 2004}

Frente a la sistemática represión que el Estado chileno desarrolla en contra de personas y comunidades mapuche y que durante estos días ha intensificado para dar continuidad a los procesos judiciales arbitrarios y condenatorios de nuestros hermanos mapuche, DENUNCIAMOS lo siguiente:

1. La actitud servil del Estado chileno y su gobierno ante las presiones del empresariado nacional y transnacional que ha visto afectada sus inversiones en territorio mapuche. Esto se hace más que evidente cuando día a día políticos de derecha, dirigentes gremiales de los empresarios e incluso parlamentarios de la concertación hacen públicas sus opiniones exigiendo la persecución y represión de dirigentes y comuneros que han sostenido una lucha digna por los derechos mapuche.

2. El publicitado Estado Derecho no es más que la expresión de un sistema político afín y subordinado a los intereses del sistema económico capitalista, donde las demandas por territorio y autonomía mapuche son fuertemente reprimidas. Por ello, el Estado de Derecho no es más que un mecanismo de protección a las inversiones que desarrollan las empresas forestales, turísticas y energéticas en el territorio ancestral mapuche.

3. La fuerte y desproporcionada represión que han llevado a cabo los organismos policiales del Estado chileno en contra de nuestras comunidades, allanando, amenazando y violentando la vida de nuestras familias, resultando más grave aún el atropello a nuestras autoridades como lonko y machi de las comunidades, así también de nuestros fücha keche ka pichi keche [ancianos y niños mapuche].

4. Como se ha hecho público, estas acciones policiales están debidamente respaldada por una orden del tribunal respectivo y no son más que la represión brutal que 
refleja las injusticias a las que históricamente ha sido sometido nuestro Pueblo Nación Mapuche.

5. Este atropello no aniquilará a nuestras comunidades y nos da cada día más fuerza para seguir luchando y resistiendo. La lucha digna por nuestros derechos políticos y territoriales surge con más fuerza y nos impulsa a seguir la resistencia contra las empresas forestales y latifundistas que se han enriquecido con los recursos naturales de nuestras tierras mapuche.

6. Respaldamos a las personas y comunidades mapuche que transitan por la línea de la autonomía y respaldamos las acciones de resistencia que desarrollan y desarrollarán nuestras comunidades por la defensa de nuestra dignidad y nuestros derechos como Pueblo Nación Mapuche."

"fuera las forestales del territorio mapuche... no más represión a nuestras comunidades,... libertad a los presos políticos mapuche".

ii w e u w a i ñi

COORDINADORA DE COMUNIDADES MAPUCHE EN CONFLICTO ARAUCO MALLECO

Desde Territorio Mapuche, 30 de julio de 2004

\section{DECLARACION DE COORDINADORA MAPUCHE} REGION METROPOLITANA

Santiago, Diciembre de 1997

"No somos minoría étnica, somos un pueblo y no descansaremos hasta lograr que la dignidad retorne para todo el Pueblo Mapuche."

\section{NEWENTULEAINY}

RALKO KA LUMACO !

Fuerza Ralco y Lumaco!

"La familia mapuche se reúne, para reconocerse y decir que está orgullosa de ser mapuche, que nuestros rostros, apellidos, costumbres, sangre, como también nuestro lugares de origen, son algunas de las cosas que tenemos en común y que aunque estamos en una gran ciudad queremos y debemos estar unidos, diciendo soy parte del Pueblo Mapuche" (Autoafirmación identitaria)

DIGNIDAD PEWENCHE.

\section{NO A LA REPRESA RALCO !}

En la precordillera de la 8va región, a 85 kilómetros de Los Angeles, zona donde nace el río BioBio se inauguro en marzo de 1997 la Central Hidroeléctrica Pangue, la primera de un megaproyecto de 6 represas generadoras de electricidad. (anclaje)

Actualmente pese a no contar con la autorización definitiva, se esta instalando maquinaria pesada para iniciar los trabajos de la segunda represa, RALKO, la cual in- 
undaría 3.400 hectáreas de territorio Pewenche, previa erradicación de las familias allí asentadas por siglos.

ENDESA, empresa privada dueña del proyecto presiona para trasladar a las familias a lugares donde la sobrevivencia se pone en peligro. Muchos de los peñi y lamgen de las comunidades afectadas han resuelto NO SALIR de sus ancestrales territorios. No permitirán que los cementerios de sus antepasados sean inundados, ni permitirán cambiar sus tierras bajo ningún precio.

Los hermanos pewenche son constantemente amenazados para que firmen documentos para permutar las tierras, las autoridades de gobierno, es decir, los actuales administradores del Estado Chileno, totalmente partidarios de la construcción de la represa, avalan solo los intereses del empresariado privado, dando continuismo a la discriminación, pobreza y marginalidad en que ha pretendido enmarcar al Pueblo Mapuche.

Queremos respeto a nuestra historia, idioma, costumbres, tierras, podemos y queremos decidir donde vivir.

\section{JUSTICIA PARA LUMAKO !}

Una fuerte represión han debido soportar comunidades mapuches de Lumako como Pichi Linkoyan o Pillin Mapu, al reclamar la restitución de sus territorios, ocupados actualmente por la empresa Forestal Bosques Arauco. Esta arremetida se focaliza el la provincia de Malleco 9o región del país, con una militarización de la zona, amedrentamientos, y doce mapuches detenidos, procesados bajo la ley de Seguridad Interior del Estado.

Durante semanas el gobierno y la prensa sensacionalista, formula acusaciones infundadas, tratando de encubrir la situación de fondo: la escasez de tierras, una de las principales causales que lleva nuestra gente a sobrevivir en la extrema pobreza. La aplicación de la ley de Seguridad del Estado, nos da a entender que cuando se trata de defender los intereses de los poderosos, el gobierno no repara en los métodos a utilizar, pasando desde la represión directa hasta una represión oculta y silenciosa, tratando de generar inseguridad y miedo en las familias mapuches de las comunidades de Lumako.

Estas prácticas que afectan al conjunto de la sociedad chilena conlleva la aplicación de la doctrina se seguridad nacional, la cual en su aspecto evidente reprime todo tipo de manifestaciones que cuestionen el orden que nos rige, con mayor razón cuando el cuestionamiento es a los usurpadores que nos han dejado escasas e infértiles tierras. EXIGIMOS UNA SOLUCION A LAS DEMANDAS DE TIERRAS, LA LIBERACION INMEDIATA DE LOS MAPUCHES ENCARCELADOS, COMO TAMBIEN EL RETIRO DE LA LEY DE SEGURIDAD INTERIOR DEL ESTADO. Ralko y Lumako son solo una parte de la situación que vive nuestro Pueblo Mapuche. Esto debe ser cambiada entre todos, no tan solo entre mapuches y otros pueblos originarios, sino que también con toda la sociedad chilena, ya que la mayoría de los sectores sociales del país comparten con algunos de nosotros, ya sea en el trabajo, lugares de estudio o en el barrio, presentándonos el desafío de practicar una tolerancia mutua y respeto a la diversidad. 
Somos un Pueblo y tenemos derecho a manifestar libremente nuestro descontento cuando el autoritarismo del poder económico destruye la ñuuke mapu (madre tierra) y a la gente que es parte de ella, mapuche.

Lo que ocurra en las comunidades del sur, es nuestra preocupación. Allá esta toda nuestra historia, nuestros antepasados, toda la sabiduría, solo a partir de este siglo los mapuches habitan las grande ciudades, pero no olvidamos a nuestra gente del sur, viajando constantemente. Ya empieza la época de las cosechas, ya viene la chicha de manzana dulce, y la gran mayoría viajaremos al campo y junto con saludar y acompañar a nuestros parientes, compartiremos un mate con pan amasado.

Somos la misma gente de la tierra.

EXIGIMOS LA LIBERTAD INMEDIATA PARA LOS MAPUCHES ENCARCELADOS, COMO TAMBIEN QUE NO SEA APLICADA LA LEY DE SEGURIDAD INTERIOR DEL ESTADO. LA REPRESA RALKO NO DEBE CONSTRUIRSE. EL ALTO BIO BIO ES PEWENCHE.

MARRICHIWEU KOM PUCHE ! NEWENTULEAINY! RALKO KA LUMAKO ! COORDINADORA MAPUCHE REGION METROPOLITANA Diciembre, 1997

\section{DECLARACIÓN PÚBLICA}

La Coordinadora Mapuche de la IX Región, ante la reunión del Consejo de la CONADI a efectuarse en Santiago, la que tiene por objeto el pronunciarse respecto de las permutas de Tierras frente a la construcción de la Represa Ralco, en el Alto Bío-Bío, denuncia ante la opinión pública Nacional e Internacional, lo siguiente:

Esta reunión del Consejo de la CONADI, no tiene ninguna validez legal, en cuanto a la decisión de permuta de tierras, ya que, la Ley Indígena en su artículo $\mathrm{N}^{\circ} 13$ no permite la enajenación de las mismas cuando uno de sus comuneros se opone. ¿Bajo qué fundamento entonces, estos consejeros se atribuyen el derecho de tomar dicha decisión?. En esta lucha de intereses económicos los consejeros (todos), han sido negligentes y serviles a intereses de la Transnacional y del Gobierno.

$\mathrm{Ni}$ Namuncura, ni sus consejeros se han pronunciado respecto a las obras de construcción de la Represa que se efectúa ya desde varios meses en el Alto Bío-Bío, todos estos señores avalan con su actitud hipócrita el objetivo de ENDESA de construir Ralco por la vía de los hechos consumados, esto fundamenta y adjetiva esta convocatoria del Consejo de la CONADI como oportunista, trasnochada y de última hora.

La política de este Gobierno, supuestamente Democrático, frente a las demandas de los Pueblos Indígenas, ha sido irresponsable, inhumano y contradictorio. Ellos saben muy bien la situación de pobreza en que se encuentran las comunidades Pewenche, por efecto de las políticas económicas que han implementado en los últimos 
25 años, a las que se suman actitudes de racismo manifiesto en cuanto a buscar soluciones a los problemas que como pueblo tenemos. En el actual gobierno y en el anterior, frente a un tema tan importante para el país como es Ralco, ha dejado e los Pewenche en el más grande desamparo en su lucha contra un gran monstruo como es ENDESA, la ética, la moral y el honor dejan en evidencia que este gobierno se ha desentendido del problema, han hecho oídos sordos ante la denuncia de nuestras autoridades, en consecuencia han amparado con su silencio a los más poderosos.

Denunciamos y protestamos ante la opinión pública, por las constantes violaciones a nuestros derechos de Pueblo y a nuestros derechos humanos que como personas tenemos. Este gobierno y el anterior han suscrito acuerdos internacionales y en otros se han ratificado en el marco de los derechos humanos, pero en la práctica todo esto ha quedado en el protocolo. Cada día que pasa aumenta el proceso de migración a las grandes ciudades, ya que en las comunidades no hay posibilidades de desarrollo; el deterioro de las Tierras por la erosión y falta de agua en muchos lugares hace imposible la vida en esas Tierras.

Entendemos que el conflicto de Ralco puede llegar a los Tribunales de Justicia en donde se sopese las leyes en diferencia, osea la Ley Indígena y la Ley de Electricidad, donde obviamente la salida será política. El Pueblo Mapuche y en particular los Pewenche, lucharemos por la defensa de nuestra tierra, nuestra identidad y nuestra cultura, que nadie tenga duda al respecto. Exigimos de los parlamentarios, de la Iglesia, de las personalidades públicas y culturales, un pronunciamiento por los graves hechos que lesionan nuestra dignidad, nuestro honor y nuestro respeto.

Coordinadora Mapuche IX Región

Temuko, Julio 23 de 1998

\section{COMUNICADO PUBLICO}

Las comunidades mapuche, Antonio Niripil del sector Temulemu, y Lorenzo Norin, del sector de Didaico de la Comuna de Traiguen, comunicamos a nuestras comunidades, Organizaciones y a la opinión pública en general, que:

Con fecha 20 de Septiembre nos propusimos recuperar 66 hás de tierra que nos tiene usurpada el Fundo Santa Rosa de Kolpi, hoy propiedad de la Forestal Mininco. Hemos permanecido ya por 10 días en nuestra tierra, en el transcurso de estos días hemos tratado de conversar con los representantes de la Empresa, quienes se han negado a recibirnos, nuestra intención es establecer una conversación con los representantes de la forestal para fijar plazos de entrega y la necesaria indemnización que nos debe hacer la Empresa por los más de 70 años que han usufructuado de nuestra tierra.

Con fecha de hoy 30 de Septiembre, nos dispusimos a explotar el bosque existente en nuestro predio de las 66hás. Producto de ello, se ha hecho presente en el terreno, Juan Carlos Navia representante de Mininco en compañía de un número importante de carabineros. 
Queremos dejar de manifiesto, nuestra firme decisión de recuperar nuestras tierras, por cuanto ésta la habíamos recuperado el año 1972 y producto del golpe militar de 1973 nuevamente se nos fue arrebatada por parte de la Forestal Crecet.

Dejamos claro, que los hechos de violencia que pudieran ocurrir en el lugar como producto de un posible desalojo, son de exclusiva responsabilidad de la Empresa y Carabineros de la zona.

\section{POR LAS COMUNIDADES EN CONFLICTO}

Traiguén, 30 de Septiembre de 1998.

\section{COMUNICADO DE PRENSA}

En el día de hoy se cumplen 505 años de la llegada de los conquistadores Españoles a nuestro territorio, en esta fecha ha cambiado radicalmente nuestra vida como Pueblos Indígenas. A partir de esta fecha somos pueblos oprimidos hasta el día de hoy. Desde ese momento se desencadenó todas las formas de violencia y violación de nuestros derechos y libertades fundamentales.

Hace 505 años se hizo presente la opresión política, la negación de nuestros derechos, la usurpación de nuestras tierras y territorio, se hizo presente la violencia con todas sus manifestaciones. De la misma manera en muchos de los casos se hizo presente el genocidio con los Pueblos Indígenas. Todas estas políticas colonialistas y tratos inhumanos respondían a los intereses expansionistas del naciente capitalismo europeo liderado por España. Durante este periodo de la historia Europa buscaba en otro punto de la tierra hacer posible su enriquecimiento. Para conseguir sus objetivos tuvieron que aplicar políticas inhumanas y degradantes que avergüenzan la historia de la humanidad.

Cabe subrayar que las políticas de expansión, de ocupación territorial e lo ajeno y negación de nuestros derechos más elementales no ha terminado. No son hechos que ocurrieron en el pasado . Al contrario, muchos de los métodos se han sofisticado se han modernizado de todo punto de vista."

\section{AUKIÑ WALLMAPU NGULAM -CONSEJO DE TODAS LAS TIERRAS. WALLMAPUCHE, 12 DE OCTUBRE DE 1997.}

